\title{
Ambulatory Assessment in Lifespan Psychology
}

\section{An Overview of Current Status and New Trends}

\author{
Christiane A. Hoppmann ${ }^{1}$ and Michaela Riediger ${ }^{2}$ \\ ${ }^{1}$ University of British Columbia, Vancouver, BC, Canada, ${ }^{2}$ Max Planck Institute for Human \\ Development, Berlin, Germany
}

\begin{abstract}
Ambulatory assessment represents a powerful research tool in lifespan psychology because it allows assessing the within-person variability of developmental processes as it occurs within context-specific influences of people's natural environments. Following a discussion of historical origins, we review four current research themes in developmentally relevant ambulatory assessment studies that use electronic devices as assessment instruments: (a) affective-motivational development, (b) social contexts of development, (c) age-related challenges and everyday functioning, and (d) cognitive development. Overall, the reviewed research demonstrates that ambulatory assessment complements traditional developmental study designs and laboratory assessments in important ways. Acknowledging the strengths and limitations of ambulatory assessment approaches, we propose that ambulatory assessment will benefit lifespan psychology most if it becomes an integral part of multimethod investigations of developmental phenomena that balance the external and internal validity of findings. Future research should strengthen the lifespan perspective in ambulatory assessment approaches, combine multiple indicators (subjective and objective) of successful development, and attend to the fact that individual development often interacts with significant others.
\end{abstract}

Keywords: lifespan psychology, ambulatory assessment, intraindividual variability

\section{Introduction}

Observing developmental phenomena as they unfold in people's everyday lives and natural environments has been a core interest of developmental psychologists since the early days of the discipline (Buehler, 1930). Among the earliest naturalistic observation methods are child biographies in the form of detailed developmental logs on single individuals (Buehler, 1930; Darwin, 1877; Piaget, 1928). Jean Piaget, for example, frequently referred to child biographies from his own children when illustrating his developmental propositions throughout his career (Piaget, 1928). For his work on moral development he also extended this method beyond the use of single case studies. Piaget observed hundreds of marble playing children in the streets of Geneva and Neuchatel and analyzed their understanding and interpretation of the game rules (Piaget, 1932). Behavioral observations in daily-life contexts have also been used at the opposite end of the lifespan. Margret Baltes, for example, investigated mechanisms of dependency in old age by systematically observing daily social interactions in nursing homes (Baltes \& Zerbe, 1976). Over the past 2 decades, lifespan psychologists have increasingly emphasized the need to address the dynamic nature of developmental processes in natural contexts using microlongitudinal designs (Almeida, Wethington, \& Kessler, 2002; Nesselroade \& Salthouse, 2004; Sliwinski, Smyth, Hofer,
$\&$ Stawski, 2006). Among the terms used are ambulatory assessment, diary method, event-sampling method, beeper studies, real-time reporting techniques, time-situated methods, intensive repeated-measures methods, or ecological momentary-assessment methods. As plentiful as their labels are the specific assessment techniques. They include video-based behavioral observations (Kreppner, 2005), daily phone interviews (Almeida et al., 2002), instant messaging (Igarashi, Takai, \& Yoshida, 2005), paper diaries (Riediger \& Freund, 2004), repeated home interviews (Gerstorf, Smith, \& Lindenberger, 2006), repeated in-lab sessions (Sliwinski et al., 2006), electronic sound recordings (Mehl \& Holleran, 2007), electronic pagers (Klumb \& Baltes, 1999), or pocket computers (Hoppmann \& Klumb, 2006). For this overview, we selectively focus on one specific approach to implementing microlongitudinal study designs, which is characterized by the use of electronic devices such as beepers or pocket computers for the repeated sampling of momentary experiences as people undergo their daily life routines in their natural environments. In the following, we adopt the label ambulatory assessment to refer to this assessment approach (see Bolger, Davis, \& Rafaeli, 2003; Fahrenberg, Myrtek, Pawlik, \& Perrez, 2007; Feldman Barrett \& Barrett, 2001; Hektner, Schmidt, \& Csikszentmihalyi, 2007; Reis \& Gable, 2000; Stone, Shiffman, \& DeVries, 1999 for reviews).

We start out by introducing lifespan-theoretical concepts 
that are relevant to ambulatory assessments. We then present contemporary lifespan research using ambulatory assessments concerning four areas: (a) affective-motivational development, (b) social contexts of development, (c) agerelated challenges and everyday functioning, and (d) cognitive development. We finally discuss both benefits and challenges of ambulatory assessments from a lifespan perspective, and propose new directions for future research.

\section{Conceptual Foundations of Ambulatory Assessments in Lifespan Psychology}

Development has been defined as a dynamic process of selective adaptation to changing circumstances that extends across the entire lifespan, from conception to death (Baltes, Lindenberger, \& Staudinger, 2006). There are three important reasons why microlongitudinal designs, in general, and ambulatory assessments, in particular, represent an important tool for investigating developmental psychological phenomena: First, repeated observations allow for an investigation of intraindividual variability and change. Past research has often attempted to describe developmental phenomena based on age-group comparisons using single occasion data or relatively long measurement intervals, such as years. While this approach is certainly valid for some questions, it is fundamentally limited because interindividual differences do not necessarily translate into intraindividual change in development (Molenaar, Huizenga, \& Nesselroade, 2003; Siegler, 2002; Sliwinski et al., 2006). Furthermore, relatively long time spans between measurement points bear the risk that short-term fluctuations or developmental changes that take place on smaller time scales, such as minutes, hours, or days, and that potentially affect long-term outcomes, are missed (Li, Huxhold, \& Schmiedek, 2004; Nesselroade \& Salthouse, 2004; van Geert \& van Dijk, 2002). As a result, lifespan psychology has recently witnessed a renewed interest in studying intraindividual variability within and across domains of functioning. Such investigations require microlongitudinal designs, that is, obtaining a large number of repeated measurements at short intervals. Ambulatory assessment is one way of implementing such designs.

Second, ambulatory assessments realize microlongitudinal designs in daily life contexts. The benefits of complementing attempts to isolate specific developmentally relevant mechanisms under well-controlled laboratory conditions with investigations of developmental phenomena as they occur within the complexity of people's own environments have long been recognized theoretically (Baltes et al., 2006). Ambulatory assessment procedures offer a methodological tool that is well suited for examining developmental processes as they occur within complex, realworld contexts. They not only address theoretically, but also assess in actuality, the specific environmental factors that participants are confronted with as they move through different environmental contexts. Furthermore, ambulatory assessments that use electronic assessment devices combine some key strengths of lab-based assessments and paper diaries by maximizing ecological validity while preserving a relatively high level of experimental control. For example, time-stamped assessments allow an examination of compliance with the study protocol. Advances in computerized ambulatory-assessment technology also make implementations of complex sampling schedules possible, an important means of increasing the representativeness and generalizability of obtained experience samples.

Third, an important source of information in much developmental research is the individual him- or herself. Ambulatory assessment procedures assess experiences as they occur, or close to their occurrence, and thus, help to reduce an important limitation of self-reports: retrospective response biases. Self-reports often necessitate complicated reconstructions of past behaviors and feelings that are based on a multitude of heuristic mechanisms by weighing chronically and currently accessible information and that are prone to systematic biases. In general, single-occasion retrospective self-reports seem to be more vulnerable to such response biases than momentary ratings (Schwarz, 1999). This may be particularly relevant to aging research because such biases can be more pronounced in individuals with decreasing fluid-cognitive functioning, such as older adults (Klumb \& Baltes, 1999).

Fourth, while reduced self-report biases represent an important advantage that also applies to diary studies, ambulatory assessments are not restricted to the assessment of self-reports. Another interesting feature of ambulatory assessments is the possibility of administering computer-assisted timed tasks, for example, cognitive testing, as people engage in their everyday routines.

In short, electronic ambulatory-assessment procedures represent a powerful research tool in lifespan psychology because they (a) attend to dynamic developmental processes, (b) combine high ecological validity with experimental control, (c) minimize self-report biases that may be particularly relevant in old age, and (d) allow the administration of timed performance-based tasks in addition to self-report information.

\section{Ambulatory Assessment in Current Lifespan Psychology: An Overview of Four Areas of Investigation}

We identified the literature for the following overview through searches for the methodological keywords timesampling, event-sampling, ambulatory assessment, experience sampling, ecological momentary assessment, daily diaries, and within-person variability in the databases PsychInfo and Medline, restricting the latter to nonclinical populations. Additional references were derived from review articles and follow-up searches for primary authors. 
Inclusion criteria were that the reported research used beepers or pocket computers as assessment devices and was developmentally relevant. Apart from research that explicitly investigated developmental research questions, we also considered studies to be developmentally relevant when developmental insights could be derived from placing the research in the context of other studies investigating, for example, other age groups. A table summarizing the identified studies is available at www.ambulatory-assessment. org/fileadmin/user_upload/additional_material/Hoppmann _Riediger_09.pdf. In the following paragraphs, we present a subset of these studies to illustrate the benefits and challenges of ambulatory assessments in lifespan psychology. The presentation of studies follows four broad research domains: (a) affective-motivational development, (b) social contexts of development, (c) management of age-related challenges and everyday functioning, and (d) cognitive development.

\section{Development of Affective- Motivational Processes in Daily Life}

In the following section we highlight research using ambulatory assessments to address emotional experiences and motivational processes across the lifespan. Participants in the identified studies ranged from school-aged children (Larson, Csikszentmihalyi, \& Graef, 1980) to 97 years (Hoppmann, Gerstorf, Smith, \& Klumb, 2007). Most research, however, is based on college students and middleaged populations.

Age-related changes in emotional experiences have attracted a lot of interest in lifespan psychology, in part, because they represent a domain of functioning where growth is possible until relatively old age (Baltes et al., 2006). Specifically, it has been proposed that with advancing age, people optimize their emotional experiences and become better at regulating their emotions (Blanchard-Fields, 2007; Carstensen, Pasupathi, Mayr, \& Nesselroade, 2000). In this section, we discuss ambulatory assessment studies that address key hypotheses concerning age-related changes in emotional functioning. For example, questions concerning age-related differences in intraindividual affect variability can include whether older adults experience certain emotional states less frequently or with lower intensity than younger adults, how long emotional experiences persist, and if older adults experience more emotions at the same point in time than young adults. Furthermore, ambulatory assessment studies provide information about correlates and consequences of daily emotional experiences across the lifespan, for example, their interrelations with motivational processes and health indices.

There is considerable evidence that daily affective experiences vary systematically across different life phases (Carstensen et al., 2000; Larson et al., 1980). Based on up to 70 randomly sampled affect-reports from an adolescent to middle-aged adult sample, Larson and colleagues (1980) show that adults' mean affect levels were considerably higher than those of adolescents. In addition to these agerelated differences in average levels of emotional well-being, daily affective experiences also show remarkable age effects in their within-person variability. Specifically, Larson and colleagues (1980) showed that adolescents exhibit greater intraindividual variability in daily affect as compared to young and middle-aged adults. That is, adolescents experience comparatively wider, and also quicker, mood swings. A second study by Carstensen and colleagues (Carstensen et al., 2000), which randomly sampled up to 35 affect reports in a sample aged 18 to 94 years confirms and extends these finding in important ways. They show that older adults experience fewer negative emotions and just as many positive emotions as young and middle-aged adults. These findings further corroborate the picture of a positive development in daily-life affective experiences into older adulthood. In addition to mean level findings, they also report considerable age-related differences in daily affect variability. Specifically, older adults' positive affective experiences lasted longer, whereas their negative affective experiences were more short-lived than those of young and middle-aged adults. In addition, Carstensen and colleagues provide evidence that older adults show a greater emotional complexity, based on P-factor analysis, than their younger counterparts, again illustrating that emotional functioning represents a domain that is relatively spared from aging-related losses, at least into young old age (Carstensen et al., 2000).

Another set of ambulatory assessment studies addresses the question of what characterizes situations that are related to elevations in affect and how affect quality corresponds to important health indices across the lifespan. Based on 1 week of ambulatory assessments in a middle-aged sample and an older adult sample, Hoppmann and colleagues (Hoppmann et al., 2007; Hoppmann \& Klumb, 2006) emphasize the role of goal-related activities. They show that middle-aged and older adults report higher positive affect when engaging in activities that further age-related goals than when engaging in goal-irrelevant or goal-hindering activities. Hence, daily affect seems to be tied to the relevance of daily activities in terms of personal goals throughout adulthood even though the specific content of those goals may be age-specific. Additionally, goal-relevant activities were also linked with concurrent physiological arousal and long-term outcomes (Hoppmann et al., 2007; Hoppmann \& Klumb, 2006). Specifically, the performance of goal-furthering daily activities and the experience of positive-affect qualities were both associated with a decreased secretion of an important stress hormone, namely, cortisol (Hoppmann \& Klumb, 2006). This finding was confirmed by Adam and colleagues (Adam, Hawkley, Kudielka, \& Cacioppo, 2006), who show similar concurrent relationships between affect and cortisol in an older adult sample. Importantly, they also provide evidence regarding its causal order. Specifically, they show that negative affec- 
tive experiences were linked to a next-day morning rise in cortisol and not the other way around (Adam et al., 2006). Finally, findings from the other older adult sample (Hoppmann et al., 2007) further indicate that older adults who engaged in activities that were associated with age-related goals also had a higher probability of survival 10 years later.

Overall, the reviewed studies illustrate age-related differences, both in the average level and the within-person variability of daily affective experiences. Momentary affective experiences in daily life appear to show positive age trajectories from adolescence to young old adulthood. The reviewed research further demonstrates that intraindividual affect variability is linked to goal-related processes, and that it has immediate as well as long-term consequences for the individual's health and well-being. It demonstrates that ambulatory assessment adds to our understanding of the development of affective-motivational phenomena, and, thus, complements traditional developmental study designs and laboratory assessments in important ways. When looking at the optimistic picture concerning age-related increases in affective functioning, however, it is important to keep in mind that several of the reported studies are based on a positive selection of resource-rich participants. For example, the study by Hoppmann and Klumb (2006) sampled middle-aged adults with a high socioeconomic status. Similarly, one of the older adult samples (Hoppmann et al., 2007), comprised relatively high-functioning participants in terms of cognitive and sensory functioning. This sample selectivity is related to two important issues that need to be addressed in future research. First, it remains to be demonstrated whether the reported age-related increases in affective functioning are restricted to samples of successful agers or whether they generalize to populations with fewer resources. Second, it raises the question of minimum requirements concerning tactile skills and cognitive abilities that may limit the implementation of ambulatory assessments in certain age-groups, e.g., young children and older adults.

Whereas the studies reviewed so far focused on single individuals, other research using ambulatory assessment acknowledges the inherently social nature of human development. This research, which we review in the next section, has combined developmental and social-psychological research perspectives. Some of it has targeted affective processes, but other domains of functioning have also been addressed.

\section{Social Contexts of Development}

The second group of studies reviewed here examines social-psychological phenomena across the lifespan. Although participants in the reported studies ranged in age from 5th grade adolescents (Larson \& Richards, 1994) to $61+$ years of age (Janicki, Kamarck, Shiffman, \& Gwaltney, 2006), overall, children and older adults are seriously underrepresented in this line of research.
The relationship literature shows fairly predictable changes in network composition and functions as people move through different life phases. For example, in comparison to earlier life phases, social networks of older adults typically are smaller, composed of more kin than nonkin, and characterized by considerable closeness. In addition, social relationships are increasingly motivated by the exchange of emotional meaning (Antonucci, Akiyama, \& Takahashi, 2004; Carstensen et al., 2000). Lifespan research increasingly recognizes the fact that studying the development of social phenomena requires the simultaneous investigation of multiple social-network members (Baltes \& Staudinger, 1996). Consequently, the research discussed next examines daily-life processes in the context of age-specific relationships, such as affect transmission across multiple network members.

Using affect reports, randomly sampled during 1 week from adolescents, fathers, and mothers, Larson and Richards (1994) targeted interdependencies in affective experiences within family systems. Overall, they show modest associations between affective states of different family members that are, however, highly specific to the family members involved. Specifically, the authors found that adolescent girls' affect had a particularly strong effect on mothers' and fathers' subsequent affective experiences, while fathers' affect influenced son's and mother's affect. These findings suggest that affective experiences within family systems may be lifephase specific and differ systematically across different family roles. Adolescents typically do not only interact with members of their immediate family but increasingly engage with other nonkin peers. Totterdell (2000) employed ambulatory assessment methods in one particular type of peer network, namely sports teams, and examined affect transmissions between cricket players. His study shows that individual players are susceptible to the mood of other team members. Interestingly, such affect transmissions were more pronounced for positive as compared to negative affective states. In addition, associations between individual and team affect were stronger for older, more committed players. Players' moods were further related to subjective performance outcomes (Totterdell, 2000). Taken together, the findings from these two studies suggest that adolescents and young adults are susceptible to affective experience of other network members and that processes of affective transmission may operate differently in kin and nonkin networks.

Another naturally occurring unit that lends itself to an investigation of the development of social-interactive processes and that plays an increasingly important role throughout adulthood is romantic couples. Ambulatory assessment based studies targeting midlife couples point to a close association between spousal activities, relationship satisfaction, and physiological activation (Klumb, Hoppmann, \& Staats, 2006a, 2006b). For example, Klumb and colleagues (Klumb et al., 2006a) demonstrate that spousal relationship satisfaction is not only related to each individual partner's own activities but also to those of the respective spouse. In addition, 
individual as well as spousal activities were related to the secretion of cortisol. Specifically, after accounting for both partners' work-related activities, an individual's household work was associated with an increased cortisol secretion, whereas the respective partner's household work was associated with a decreased cortisol secretion (Klumb et al., 2006b). These findings indicate that midlife spouses' psychological and physical well-being are linked to not only their own behavior but also to the behavior of the respective spouse. Janicki and colleagues (Janicki et al., 2006) extend this research on the relationship between spousal behaviors and relationship satisfaction in a sample of elderly spouses. Using 2-day ambulatory-assessment information, they show that elderly spouses with high marital adjustment reported more spousal interactions, and evaluated these interactions as being less conflictual and more agreeable than spouses with low marital adjustment. This finding converges with propositions by lifespan scholars and points to the important role of positive interactions in older adults' marital relationships.

Overall, the reviewed studies illustrate that ambulatory-assessment procedures provide important insights into the development of both contents and contexts of daily social activities and experiences. Although developmental research in this area has only just begun to evolve, the available studies demonstrate that understanding human development requires investigations that go beyond single individuals. Considering social contexts in ambulatory-assessment studies, both within naturally occurring kin and within nonkin units, is an important step in this direction. Despite the possible benefits, ambulatory-assessment studies in this area should address the following challenges: First, in order to disentangle personand relationship-specific effects, ambulatory-assessment studies would need to sample daily interactions with kin and nonkin network members for the same focal person. Second, it may be interesting to go beyond past conceptualizations of affective transmission and take a more fine-grained approach to examine discrete emotions. For example, it would be interesting to see if a particular emotion in one network member (e.g., anger) transmits into a qualitatively different negative emotion (e.g., anxiety) in another network member (Larson \& Almeida, 1999). Finally, studies examining social-developmental processes in older adults, such as older adult marriages, need to address the question whether the examined processes are related to age, relationship duration, or both.

\section{Management of Age-Related Challenges and Everyday Functioning}

A third group of studies addresses the daily management of specific, age-related challenges and everyday functioning in old age. The age of participants ranges all the way from second-grade children to age 97 (Klumb, 2004), but children and older adults are again underrepresented in this literature. The following ambulatory-assessment studies are organized according to the specific age-related challenges.

Educational challenges and academic achievements are themes that have attracted a lot of interest in ambulatoryassessment research investigating developmental phenomena within the age range from school age to young adulthood. One study that addresses the relationship between self-talk and academic performance is unique insofar as it applied ambulatory assessments in elementary school children (Manning, 1990). Based on 40 random beeps that were distributed over 20 school days he shows that children whose self-talk had a positive or neutral tone displayed better classroom behavior, IQ scores, and academic achievements than children who engaged in negative self-talk. These results demonstrate how ambulatory assessments can be fruitfully implemented as soon as children can write and shows that such procedures can offer insights into meaningful qualitative differences in daily activities even at a very early age.

Educational challenges continue to be important in adolescence. Apart from school, a second adolescent theme that has attracted attention in ambulatory-assessment studies is the role of solitude or time alone (Larson \& Csikszentmihalyi, 1978). Based on 42 randomly sampled selfreports from adolescents aged 13 to 18 years, Larson and Csikszentmihalyi (1978) showed that time alone generally related negatively to concurrent affect ratings. Interestingly, adolescents who spent more time alone displayed higher positive affect levels and rated themselves as more friendly and excited than adolescents who spent little time alone. Furthermore, adolescents who spent an intermediate amount of time alone were less alienated and better adjusted than those who spent either a lot or very little time alone. These findings are interpreted in relation to potential psychosocial functions of aloneness in adolescence that serve a purpose of mental reflection on, and integration of, adolescent experiences (Larson \& Csikszentmihalyi, 1978). As such, they show how developmental tasks in adolescence, for example, concerning the development of an independent identity, are realized in a daily-life context.

In young and middle adulthood, individuals typically face two major challenges: the management of work-related demands and issues concerning the combination of work and family. Based on 3-day random ambulatory-assessment information, Zohar and colleagues (Zohar, Tzischinski, \& Epstein, 2003) investigated the relationship between events relating to work goals and affect in young and middle-aged hospital residents. They showed that goal-enhancing events were associated with concurrent and end-of-day positive affect whereas goal-disruptive events were associated with concurrent and end-of-day negative affect and fatigue. This relationship was much stronger for negative as compared to positive events. Importantly, these eventaffect associations were moderated by concurrent workload, in that participants with high workloads as compared to participants with low workloads experienced even higher negative affect and fatigue when faced with goal-disrup- 
tive events and did not draw any emotional benefit from the experience of goal-enhancing events (Zohar et al., 2003). In addition to the management of work-related challenges, another central developmental challenge in middle adulthood pertains to the combination of work and family. Based on 2-week ambulatory-assessment information, Butler and colleagues (Butler, Grzywacz, Bass, \& Linney, 2005) showed that high demands on the job increase workfamily conflict and that this relationship is particularly strong among individuals with high job control. These findings may result from high control individuals taking work home when they return to their families (Butler et al., 2005). Ambulatory-assessment studies further show that conflicts and problems originating from the work and family domain are linked to affective and physiological stress reactions. Specifically, work and family stressors seem to be related to negative concurrent affect and HPA-reactivity as measured by salivary cortisol (Ockenfels et al., 1995). It is, thus, important to examine factors that contribute to the successful combination of work and family. Butler and colleagues (Butler et al., 2005), for example, identified two work-related factors, namely high control and high skills, which facilitate the combination of work and family. It is important to note, however, that the combination of work and family does not only bear a potential for conflict but also for satisfaction. In fact, DelleFave and Massimi (2004) provide evidence for the potential benefits of having stakes in both life domains. Using 400 randomly sampled self-reports covering a period preceding and following the birth of their first child, they demonstrate that new parents drew much more positive affect from their parenting activities than from any other work or leisure activity.

Recent years have also witnessed an increasing interest in ambulatory assessments in older adult samples. In fact, ambulatory-assessment procedures have proven to be a useful tool to assess older adults' daily activities, medication adherence, affect, and health even at advanced ages (Atienza, Oliveira, Fogg, \& King, 2006; Hoppmann \& Blanchard-Fields, 2008; Klumb \& Baltes, 1999; Sterns, 2005). Using 1-week ambulatory-assessment information, Klumb (2004) addressed the relationship between daily activities, social context, and affective experiences in old age. She showed that time spent alone was associated with less positive affect qualities than being in company (Klumb, 2004). This result represents an interesting parallel to the above-cited work on adolescents by Larson and Csikszentmihalyi (1978). This time alone-affect association in older adults is weaker, however, in individuals who spend a lot of time alone (Klumb, 2004). Even though the reported time-alone effect may be related to qualitative differences in activities that are typically performed alone versus in conjunction with other people, it could also point to an increased inward focus in late adulthood, which may allow reflection on past experiences.

In short, the reviewed literature demonstrates that ambulatory-assessment studies offer important insights into the management of age-related challenges. They demon- strate that the realization of these tasks is highly contextspecific. Importantly, differences in the successful management of age-related tasks are associated with subjective and physiological outcomes. Most of the available research investigated the age range from adolescence to middle adulthood. Research on young children and very old adults is slowly emerging, as reviewed in the section above. Future research may extend these novel approaches to ambulatory-based assessments to more diverse populations - especially at the beginning and the end of the lifespan.

\section{Cognitive Development}

Investigations of age-related changes in cognitive functioning have a long-standing history in developmental psychology (Baltes et al., 2006). Up to this point, however, respective studies have almost exclusively been conducted under wellcontrolled laboratory conditions, thus, maximizing the internal validity of assessments at the potential cost of limited external validity. We are aware of only two studies (Owens et al., 1998; Salthouse \& Berish, 2005) that used ambulatory-assessment procedures to address age-related differences in inter- and intraindividual variability in cognitive functioning as it occurs in people's natural environments. Both studies focused on one specific indicator of fluid-cognitive functioning that is very sensitive to change throughout adulthood, namely reaction time. Results replicated the typically observed age-related decreases in mean reaction time across the lifespan (Salthouse \& Berish, 2005). However, and very important for the purpose of this overview, they also demonstrated that intraindividual variability in reaction time is just as large as interindividual differences in reaction time (Salthouse \& Berish, 2005). This means that stable individual difference characteristics, such as age, are limited in capturing cognitive performance differences. Thus, consideration of situation-specific factors that influence cognitive performance in daily life is important to further understand age-related changes in cognitive abilities. Hence, ambulatory-assessment studies may play an important role in understanding intraindividual variability in daily cognitive performance. Owens and colleagues (1998) support this assertion by providing evidence that intraindividual variability in reaction time is related to time-of-day effects as well as daily affective experiences in a sample of young adults (Owens et al., 1998). Clearly, research using ambulatory-assessment procedures to address intraindividual variability in cognitive functioning and how it relates to specific context characteristics is in its infancy. Among the key challenges that any lifespan research using ambulatory assessments has to confront, and that particularly apply to cognitive ambulatory-assessment-based studies, are training effects and methods reactivity. Such effects are often viewed as a negative by-product of intensive sampling designs. However, they can also be utilized as novel tools for intervention purposes. Despite such challenges, this 
line of research has great potential for addressing important processes involved in cognitive aging.

\section{Open Questions and Future Directions}

The foregoing overview showed that employing ambulatory-assessment methods in the investigation of developmental research questions provides insights that could not be obtained by other methodological approaches. Ambulatory assessment, thus, represents a promising methodological tool that complements more traditional study designs and experimental investigations of developmental phenomena. It demonstrates that intraindividual variability of daily behaviors and feelings is linked to immediate and long-term developmental outcomes in various domains of functioning. In addition, the reviewed studies point to a substantial context-specificity of developmentally relevant phenomena across the lifespan. Interestingly, this is true not only for processes that one would intuitively expect to vary as individuals move through different daily-life contexts, such as affective experiences, but also for domains of functioning that have rarely been investigated in daily-life settings, such as cognitive performance.

Overall, it is notable that even though the historical origins of ambulatory-assessment methods in developmental psychology were concerned with development in childhood, today very few ambulatory-assessment studies include samples of children. In addition, and despite the fact that past research indicates the feasibility of pocket-computer-based assessments in later adulthood, up to now, few studies have investigated aging-related phenomena in older adults. This issue is related to important limitations of the use of ambulatory-assessment procedures in lifespan psychology. Specifically, computer-based testing poses minimum requirements for reading and tactile skills that may (for different reasons) restrict its use in young children and older adults. Keeping in mind these pitfalls, we want to conclude this review by proposing three key issues for future use of ambulatory assessments in lifespan psychology. Specifically, we point to the importance of (a) strengthening a lifespan perspective in ambulatory-assessment approaches and emphasize the necessity of theory-driven sampling plans. We also call for (b) combining subjective self-ratings with objective indicators of successful development, and for (c) taking the social interdependence of developmental processes into account.

\section{Lifespan Perspectives and Theory- Driven Sampling Plans Using Ambulatory Assessment}

We propose that lifespan psychology will benefit from including ambulatory assessments in lifespan-methodological study designs. To date, conclusions regarding lifespan development from past ambulatory-assessment studies have been limited for two reasons: First, much of the available research has focused on samples within very limited age ranges. Agegroup comparisons across studies are difficult or impossible because studies vary in the operationalizations of central constructs. Furthermore, most studies involve only a single ambulatory-assessment phase. Even if samples include persons of different ages, such designs do not allow disentangling aging-related effects from cohort-related and normative history-graded influences. To maximize their contributions to lifespan psychology, we propose that ambulatory-assessment modules be implemented in longitudinal and, ideally, crosssequential designs in the future. In other words, we deem it important to obtain information on repeated ambulatory-assessment phases within sequentially sampled age-heterogeneous samples in order to maximize the contributions of ambulatory assessments to lifespan psychology.

A second and closely related methodological challenge to be addressed in future research pertains to selection of sampling plans within and across ambulatory-assessment phases. In other words, one of the greatest challenges in ambulatory-assessment studies relates to the question of who to sample, when, and how often. Theoretically sound definitions of time-sampling plans depend on specifics of the phenomenon of interest and require that close attention be paid to expected time scales and critical age periods. For example, affective experiences vary as individuals move through different dailylife contexts (Hoppmann et al, 2007; Riediger \& Freund, 2004, 2008). In order to capture context-specific daily fluctuations in affect, it is imperative that researchers sample affect ratings on short time scales that correspond to the specific research question. We also know that mean levels of daily affect as assessed by ambulatory-assessment methods follow positive trajectories across adulthood. As of yet, though, no ambulatory assessments of affective states have targeted very old adults approaching death. Survey studies, however, have demonstrated that the general psychological well-being of individuals drops significantly as they approach the end of life (Gerstorf, Ram, Röcke, Lindenberger, \& Smith, 2008). This change in mean levels occurs along longer time spans involving months or years. Hence, if researchers want to address key theoretical questions, such as whether attenuated intraindividual variability in affect is linked to long-term change in terms of a systems breakdown prior to death, they need to identify individuals who are approaching this life phase, follow them up over months or years, and investigate their daily affective experiences using repeated measurement bursts (Baltes \& Smith, 2003; Hertzog \& Nesselroade, 2003; Li et al., 2004; Nesselroade \& Ghisletta, 2003). Other examples of simultaneous processes that operate along different time-scales are the development of language in childhood (van Geert \& van Dijk, 2002), and the transition to parenthood (Delle Fave \& Massimi, 2004). 
We propose that researchers need to make theory-driven choices of adequate sampling of participants and suitable scheduling of ambulatory assessments over time in order to maximize insights into longer-term within-person development while at the same time minimizing the risk of missing meaningful short-term intraindividual fluctuations. We also want to note that some of the above mentioned questions can also be addressed using other microlongitudinal designs. For example, pocket computers may restrict the range of tasks that can be presented. As a result, some research focusing on specific cognitive measures may be better off using laboratory-based assessments (Sliwinski et al., 2006). In a similar vein, some populations (such a chronic pain patients) may not be comfortable using pocket computers (Green, Rafaeli, Bolger, Shrout, \& Reis, 2006; Newth \& DeLongis, 2004). Research targeting such populations may benefit from the use of paper diaries. Finally, some research questions may be best addressed using open-ended response formats. Novel alternatives to the use of paper diaries may include but not be restricted to combinations of pocketcomputer-based questionnaires and audio-recordings that can be collected using the same device or a combination of pocket-computer-based questionnaires and end-of-day qualitative recordings via telephone. Hence, ambulatory assessments represent an interesting method that complements other microlongitudinal designs. Research should make informed choices and consider the various methodological tools based on the topic and population under investigation.

\section{Combining Subjective with Objective Indicators of Successful Development}

Another important premise of lifespan research using ambulatory-assessment procedures pertains to the question of how one identifies developmental success. Despite the fact that this issue is central to almost all research conducted within the field of lifespan psychology, no standard set of criteria exists that could be used in the evaluation of developmental success. On a theoretical level, researchers agree that developmental success should be investigated using multiple criteria covering subjective, objective, and behavioral indicators (Baltes \& Carstensen, 1996; de Weerth \& van Geert, 2002; Frankenhaeuser, 1994; Schwarz, 1999). Hence, future ambulatory-assessment studies in lifespan psychology will benefit if researchers complement subjective self-reports with objective health indices, such as stress hormones, and behavioral indicators such as cognitive performance. Such an approach has the potential to reveal important insights into convergences and divergences in developmental outcomes across domains and levels of functioning.

\section{Socially Interdependent Developmental Processes}

An individual's development does not take place in isolation but is reciprocally related to his or her social and cultural context (Antonucci et al., 2004; Baltes \& Silverberg, 1994; Bronfenbrenner \& Morris, 1998). Put in terms of the interactive-minds perspective of lifespan scholars: "It is difficult for developmentalists to conceive of development as a process primarily or solely driven and organized from within the organism"(Baltes \& Staudinger, 1996, p. 2). Instead, individual development both influences and is influenced by other codeveloping persons (Baltes \& Silverberg, 1994; Baltes \& Staudinger, 1996). Past ambulatory-assessment studies have started sampling simultaneous information from multiple network members. As reviewed above, these endeavors have illustrated the benefits of investigating developmental processes within the complexities of social relationships (e.g., Klumb et al., 2006; Larson \& Almeida, 1999; Totterdell, 2000). Future research should advance our knowledge on social interdependencies in developmental processes by targeting the underlying mediating and moderating mechanisms as well as by examining the degree to which individuals of different ages benefit or suffer from the influence of other codeveloping persons (Hoppmann \& Gerstorf, in press).

\section{Summary and Conclusions}

This overview focused on contributions of ambulatory-assessment approaches in lifespan psychology. We began by delineating reasons why ambulatory-assessment procedures represent a powerful research tool in lifespan psychology. Among the features of ambulatory assessment that are particularly important from a lifespan perspective is the assessability of within-person variability, which is a recently recognized phenomenon with high relevance for lifespan research. This advantage is coupled with the accessibility of context-specific influences on development as they occur in people's daily lives and natural environments, and a simultaneous maximization of ecological validity and minimization of retrospective response biases that might be differentially relevant for persons of different ages. Following a discussion of historical origins of ambulatory assessment in lifespan research, we reviewed contemporary research themes targeting daily-life processes from a lifespan perspective. Focusing on research using ambulatory assessments with electronic devices, this research overview addressed four broad themes of investigation: (a) affective-motivational development, (b) social contexts of development, (c) age-related challenges and everyday functioning, and (d) cognitive development. The reviewed literature demonstrates that ambulatory assessment complements traditional developmental study designs and 
laboratory assessments in important ways. We conclude this overview by proposing that lifespan psychology can benefit tremendously if future research strengthens the lifespan perspective in ambulatory-assessment approaches, in terms of both recruiting lifespan samples and implementing theory-driven sampling plans for following participants over time. We also call for a stronger emphasis on combining subjective self-ratings with objective indicators of successful development, and on social interdependence of developmental processes. Overall, and acknowledging the strength as well as the limitations of ambulatory assessment-procedures, we believe that ambulatory-assessment approaches will benefit lifespan psychology most if they become an integral part of multimethod investigations of developmental phenomena, where ambulatory assessments are combined with other methodologies, thus, balancing the external and internal validity of findings.

\section{Acknowledgments}

Parts of this article were prepared while Christiane A. Hoppmann was at the Georgia Institute of Technology, on a research fellowship awarded by the German Research Foundation. We would like to thank Stephanie Gunter and Rachel Newsome for their assistance in locating the empirical articles.

\section{References}

Adam, E.K., Hawkley, L.C., Kudielka, B., \& Cacioppo, J.T. (2006). Day-to-day dynamics of experience - Cortisol associations in a population-based sample of older adults. Proceedings of the National Academy of Sciences, 103, 17058-17063.

Almeida, D.M., Wethington, E., \& Kessler, R.C. (2002). The daily inventory of stressful events. Assessment, 9, 41-55.

Antonucci, T.C., Akiyama, H., \& Takahashi, K. (2004). Attachment and close relationships across the life span. Attachment and Human Development, 6, 353-370.

Atienza, A.A., Ollveira, B., Fogg, B.J., \& King, A.C. (2006). Using electronic diaries to examine physical activity and other health behaviors of adults age 50+. Journal of Aging and Physical Activity, 14, 192-202.

Baltes, M.M., \& Carstensen, L.L. (1996). The process of successful aging. Ageing and Society, 16, 397-422.

Baltes, M.M., \& Silverberg, S.B. (1994). The dynamics between dependency and autonomy: Illustrations across the life span. In D.L. Featherman, R.M. Lerner, \& M. Perlmutter (Eds.), Life-span development and behavior (Vol. 12, pp.41-90). Hillsdale, NJ: Erlbaum.

Baltes, M.M., \& Zerbe, M.B. (1976). Independence training in nursing-home residents. The Gerontologist, 16, 428-432.

Baltes, P.B., Lindenberger, U., \& Staudinger, U.M. (2006). Life span theory in developmental psychology. In R.M. Lerner \& W. Damon (Eds.), Handbook of child psychology (6 ed., Vol. 1, pp. 569-664). Hoboken, NJ: Wiley, Inc.

Baltes, P.B., \& Smith, J. (2003). New frontiers in the future of aging: From successful aging in the young old to the dilemmas of the fourth age. Gerontology, 49, 123-135.

Baltes, P.B., \& Staudinger, U.M. (1996). Interactive minds in a lifespan prologue. In P.B. Baltes \& U.M. Staudinger (Eds.), Interactive minds: Life-span perspectives on the social foundation of cognition (pp. 1-32). New York: Cambridge University Press.

Blanchard-Fields, F. (2007). Everyday problem solving and emotion: An adult developmental perspective. Current Directions in Psychological Science, 16, 26-31.

Bolger, N., Davis, A., \& Rafaeli, E. (2003). Diary methods: Capturing life as it is lived. Annual Review of Psychology, 54, 579-616.

Bronfenbrenner, U., \& Morris, P. (1998). The ecology of developmental processes. In W. Damon \& R. Lerner (Eds.), Handbook of child psychology (Vol. 4, pp. 993-1028). New York: Wiley.

Buehler, K. (1930). The mental development of the child: A summary of modern psychological theory. New York: Harcourt, Brace, \& Company.

Butler, A.B., Grzywacz, J.G., Bass, B.L., \& Linney, K.D. (2005). Extending the demands-control model: A daily diary study of job characteristics, work-family conflict, and work-family facilitation. Journal of Occupational and Organizational Psychology, 78, 155-169.

Carstensen, L.L., Pasupathi, M., Mayr, U., \& Nesselroade, J.R. (2000). Emotional experience in everyday life across the adult lifespan. Journal of Personality and Social Psychology, 79, 644-655.

Darwin, C. (1877). A biographical sketch of an infant. Mind, 2, 285-294.

de Weerth, C., \& Geert, P. (2002). A longitudinal study of basal cortisol in infants: Intraindividual variability, circadian rhythm and developmental trends. Infant Behavior and Development, 25, 375-398.

Delle Fave, A., \& Massimini, F. (2004). Parenthood and the quality of experience in daily life: A longitudinal study. Social Indicators Research, 67, 75-106.

Fahrenberg, J., Myrtek, M., Pawlik, K., \& Perrez, M. (2007). Ambulatory assessment - Monitoring behavior in daily life settings: A behavioral-scientific challenge for psychology. European Journal of Psychological Assessment, 23, 206-213.

Feldman Barrett, L., \& Barrett, D. (2001). An introduction to computerized experience sampling in psychology. Social Science Computer Review, 19, 175-185.

Frankenhaeuser, M. (1994). A biopsychological approach to stress in women and men. In V.J. Adesso, D.M. Reddy, \& R. Fleming (Eds.), Psychological perspectives on women's health (pp. 39-56). Washington, DC: Hemisphere.

Gerstorf, D., Ram, N., Röcke, C., Lindenberger, U., \& Smith, J. (2008). Decline in life satisfaction in old age: Longitudinal evidence for links to distance-to-death. Psychology and Aging, 23, 154-168.

Gerstorf, D., Smith, J., \& Lindenberger, U. (2006, April). Perceptual speed performance in advanced old age: Short-term practice gains and links to long-term decline. Poster presented at the Cognitive Aging Conference, Atlanta.

Green, A.S., Rafaeli, E., Bolger, N., Shrout, P.E., \& Reis, H.T. (2006). Paper or plastic? Data equivalence in paper and electronic diaries. Psychological Methods, 11(1), 87-105.

Hektner, J.M., Schmidt, J.A., \& Csikszentmihalyi, M. (2007). Experience sampling method: Measuring the quality of everyday life. Thousand Oaks, CA: Sage. 
Hertzog, C., \& Nesselroade, J.R. (2003). Assessing psychological change in adulthood: An overview of methodological issues. Psychology and Aging, 18, 639-657.

Hoppmann, C.A., \& Blanchard-Fields, F. (2008, April). A comparison of ongoing and retrospective reports of everyday problem solving in elderly couples: What is real?. Poster presented at the Cognitive Aging Conference, Atlanta.

Hoppmann, C.A., \& Gerstorf, D. (in press). Spousal interrelations in old age. Gerontology.

Hoppmann, C.A., Gerstorf, D., Smith, J., \& Klumb, P.L. (2007). Linking possible selves and behavior: Do domain-specific hopes and fears translate into daily activities in very old age? Journal of Gerontology: Psychological Science, 62B(2), 104-111.

Hoppmann, C.A., \& Klumb, P.L. (2006). Daily goal pursuits predict cortisol secretion and mood states in employed parents with preschool children. Psychosomatic Medicine, 68, 887-894.

Igarashi, T., Takai, J., \& Yoshida, T. (2005). Gender differences in social network development via mobile phone text messages: A longitudinal study. Journal of Social and Personal Relationships, 22, 691-713.

Janicki, D.L., Kamarck, T.W., Shiffman, S., \& Gwaltney, C.J. (2006). Application of ecological momentary assessment to the study of marital adjustment and social interactions during daily life. Journal of Family Psychology, 20, 168-172.

Klumb, P.L. (2004). Benefits from productive and consumptive activities: Results from the Berlin Aging Study. Social Indicators Research, 67, 107-127.

Klumb, P.L., \& Baltes, M.M. (1999). Time use of old and very old Berliners: Productive and consumptive activities as functions of resources. Journal of Gerontology: Psychological Science, 54B, 271-278.

Klumb, P.L., Hoppmann, C.A., \& Staats, M. (2006a). Division of labor in German dual-earner families: Testing equity theoretical hypotheses. Journal of Marriage and Family, 68, 870-882.

Klumb, P.L., Hoppmann, C.A., \& Staats, M. (2006b). Work hours affect spouse's cortisol secretion - For better and for worse. Psychosomatic Medicine, 68, 742-746.

Kreppner, K. (2005). Family assessment and methodological issues. European Journal of Psychological Assessment, 21, 249-254.

Larson, R., \& Csikszentmihalyi, M. (1978). Experiential correlates of time alone in adolescence. Journal of Personality, 46, 677-693.

Larson, R., Csikszentmihalyi, M., \& Graef, R. (1980). Mood variability and the psychosocial adjustment of adolescents. Journal of Youth and Adolescence, 9, 469-490.

Larson, R.W., \& Almeida, D.M. (1999). Emotional transmission in the daily lives of families: A new paradigm for studying family process. Journal of Marriage and the Family, 61, 5-20.

Larson, R.W., \& Richards, M.H. (1994). Family emotions: Do young adolescents and their parents experience the same states? Journal of Research on Adolescence, 4, 567-583.

Li, S.C., Huxhold, O., \& Schmiedek, F. (2004). Aging and attenuated processing robustness: Evidence from cognitive and sensorimotor functioning. Gerontology, 50, 28-34.

Manning, B.H. (1990). A categorical analysis of children's selftalk during independent school assignments. Journal of Instructional Psychology, 17, 208-217.

Mehl, M.R., \& Holleran, S.E. (2007). An empirical analysis of the obtrusiveness of and participants' compliance with the electronically activated eecorder (EAR). European Journal of Psychological Assessment, 23, 248-257.
Molenaar, P.C.M., Huizenga, H.M., \& Nesselroade, J.R. (2003). The relationship between the structure of interindividual and intraindividual variability: A theoretical and empirical vindication of developmental systems theory. In U.M. Staudinger \& U. Lindenberger (Eds.), Understanding human development: Dialogs with lifespan psychology (pp. 339-360). Dordrecht, The Netherlands: Kluwer.

Nesselroade, J.R., \& Ghisletta, P. (2003). Structuring and measuring change over the life span. In U.M. Staudinger \& U. Lindenberger (Eds.), Understanding human development: Dialogs with lifespan psychology (pp. 317-337). Dordrecht, The Netherlands: Kluwer.

Nesselroade, J.R., \& Salthouse, T.A. (2004). Methodological and theoretical implications of intraindividual variability in perceptual-motor performance. Journal of Gerontology, 59B, 49-55.

Newth, S., \& DeLongis, A. (2004). Individual differences, mood, and coping with chronic pain in rheumatoid arthritis: A daily process analysis. Psychology and Health, 19, 283-305.

Ockenfels, M., Smyth, J., Porter, L., Kirschbaum, C., Hellhammer, D., \& Stone, A. (1995). The effect of daily hassles on salivary cortisol. Verhaltenstherapie, 5, 16-20.

Owens, D.S., Macdonald, I., Tucker, P., Sytnik, N., Minors, D., Waterhouse, J. et al. (1998). Diurnal trends in mood and performance do not at all parallel alertness. Scandinavian Journal of Work and Environmental Health, 24, 109-114.

Piaget, J. (1928). The child's conception of the world. London: Routledge and Kegan Paul.

Piaget, J. (1932). The moral judgment of the child. London: Kegan Paul, Trench, Trubner, and Co.

Reis, H.T., \& Gable, S.L. (2000). Event-sampling and other methods for studying everyday experience. In H.T. Source Reis \& C.M. Judd (Eds.), Handbook of research methods in social and personality psychology (pp. 190-222). New York, US: Cambridge University Press.

Riediger, M., \& Freund, A.M. (2004). Interference and facilitation among personal goals: Differential associations with subjective well-being and goal pursuit. Personality and Social Psychology Bulletin, 30, 1511-1523.

Riediger, M., \& Freund, A.M. (2008). Me against myself: Motivational conflict and emotional development in adulthood. Manuscript submitted for publication.

Salthouse, T.A., \& Berish, D.E. (2005). Correlates of within-person (across-occasion) variability in reaction time. Neuropsychology, 19, 77-87.

Schwarz, N. (1999). Self-reports: How the questions shape the answers. American Psychologist, 54, 93-105.

Siegler, R.S. (2002). Variability and infant development. Infant Behavior and Development, 25, 550-557.

Sliwinski, M.J., Smyth, J.M., Hofer, S.M., \& Stawski, R.S. (2006). Intraindividual coupling of daily stress and cognition. Psychology and Aging, 21, 545-557.

Sterns, A.A. (2005). Curriculum design and program to train older adults to use personal digital assistants. Gerontologist, 45, 828-834.

Stone, A.A., Shiffman, S.S., \& DeVries, M.W. (1999). Ecological momentary assessment. In D. Kahneman \& E. Diener (Eds.), Well-being: The foundations of hedonic psychology (pp. 26-39). New York: Russell Sage Foundation.

Totterdell, P. (2000). Catching moods and hitting runs: Mood linkage and subjective performance in professional sport teams. Journal of Applied Psychology, 85, 848-859. 
van Geert, P., \& van Dijk, M. (2002). Focus on variability: New tools to study intraindividual variability in developmental data. Infant Behavior and Development, 25, 340-374.

Zohar, D., Tzischinski, O., \& Epstein, R. (2003). Effects of energy availability on immediate and delayed emotional reactions to work events. Journal of Applied Psychology, 88, 1082-1093.

\section{About the authors}

Dr. Christiane Hoppmann is an assistant professor in Health Psychology at the University of British Columbia, Vancouver, BC, Canada. Her research examines the role of social and motivational processes for stress and well-being across the adult lifespan.
Dr. Michaela Riediger is head of the Max Planck Research Group "Affect Across the Lifespan" at the Max Planck Institute for Human Development in Berlin, Germany. She investigates the development of affective experiences and competencies from adolescence to old age.

\section{Christiane A. Hoppmann}

University of British Columbia

Departement of Psychology

2136 West Mall

Vancouver, BC V6T 1Z4

Canada

Tel. +1 604 822-8428

E-mail choppmann@psych.ubc.ca 